\title{
The evolutionary ecology of age at natural menopause: implications for public health
}

\author{
Abigail Fraser ${ }^{1,2}$ (D), Cathy Johnman ${ }^{1}$, Elise Whitley ${ }^{1}$ and Alexandra Alvergne ${ }^{2-4, \star}$ (iD \\ ${ }^{1}$ Institute of Health and Wellbeing, University of Glasgow, UK, ${ }^{2}$ School of Anthropology and Museum Ethnography, \\ University of Oxford, UK, ${ }^{3}$ ISEM, Université de Montpellier, CNRS, IRD, EPHE, Montpellier, France and \\ ${ }^{4}$ Harris Manchester College, University of Oxford, UK \\ ${ }^{*}$ Corresponding author. E-mail: alexandra.alvergne@umontpellier.fr
}

\begin{abstract}
Evolutionary perspectives on menopause have focused on explaining why early reproductive cessation in females has emerged and why it is rare throughout the animal kingdom, but less attention has been given to exploring patterns of diversity in age at natural menopause. In this paper, we aim to generate new hypotheses for understanding human patterns of diversity in this trait, defined as age at final menstrual period. To do so, we develop a multilevel, interdisciplinary framework, combining proximate, physiological understandings of ovarian ageing with ultimate, evolutionary perspectives on ageing. We begin by reviewing known patterns of diversity in age at natural menopause in humans, and highlight issues in how menopause is currently defined and measured. Second, we consider together ultimate explanations of menopause timing and proximate understandings of ovarian ageing. We find that ovarian ageing is highly constrained by ageing of the follicle - the somatic structure containing the oocyte - suggesting that menopause timing might be best understood as a by-product of ageing rather than a facultative adaptation. Third, we investigate whether the determinants of somatic senescence also underpin menopause timing. We show that diversity in age at menopause can be, at least partly, explained by the genetic, ecological and life-history determinants of somatic ageing. The public health implications of rethinking menopause as the by-product rather than the catalyst of biological ageing are discussed.
\end{abstract}

Keywords: Reproductive cessation; life-history; biocultural; somatic ageing; age at menopause; ovarian ageing

Media summary: Variation in age at natural menopause might be best understood as a by-product of differing rates of somatic ageing.

\section{Introduction}

Menopause, as per the World Health Organisation definition (NCC-WCH, 2015), refers to the permanent cessation of menstruation in human females. While natural menopause is a ubiquitous phenomenon of the human female ageing experience, there is considerable variation in the timing of menopause (or age at menopause), and how menopause is experienced both within, and between populations (Jasienska, Bribiescas, Furberg, Helle, \& Núñez-de, 2017; Laisk et al., 2018; Monteleone, Mascagni, Giannini, Genazzani, \& Simoncini, 2018; Sievert, 2006). To date, most research into menopause focuses either on the evolutionary emergence of menopause as a Darwinian puzzle or on the proximate determinants of ovarian ageing. Surprisingly, there have been only limited attempts at understanding patterns of diversity in age at natural menopause. This paper aims to address this deficit by developing an interdisciplinary and multilevel framework combining proximate, biomedical

(c) The Author(s), 2020. Published by Cambridge University Press on behalf of Evolutionary Human Sciences. This is an Open Access article, distributed under the terms of the Creative Commons Attribution-NonCommercial-ShareAlike licence (http://creativecommons.org/licenses/ by-nc-sa/4.0/), which permits non-commercial re-use, distribution, and reproduction in any medium, provided the same Creative Commons licence is included and the original work is properly cited. The written permission of Cambridge University Press must be obtained for commercial re-use. 
understandings of menopause with an ultimate, evolutionary ecology perspective. Considering how diversity in age at menopause is produced at one level (i.e. physiological) can help generate new hypotheses at the evolutionary level (i.e. evolutionary and ecological drivers), and vice versa. Here we build on ovarian ageing research to uncover the evolutionary ecological determinants of variation in menopause timing. In turn, we hope to stimulate a new research programme investigating whether menopause timing is best predicted by ecological models of somatic ageing.

\section{What is menopause?}

In the biomedical and population health sciences, natural menopause is defined as an event reached when a woman has not had a menstrual cycle for the past 12 months (Hillard et al., 2017). Following this final menstrual period (FMP), a woman is considered to have experienced menopause. Natural menopause, which indicates the cessation of reproductive function, most often occurs in the fourth or fifth decade of a woman's life. While menopause itself is the complete cessation of periods, it is best understood as a process rather than an event (Sievert, 2006). Indeed, individuals will be perimenopausal for some years before and after their FMP. Menopause is preceded by peri-menopause, a time period characterised by the irregularity of menstrual cycle length and frequency (Paramsothy et al., 2017) and the potential to experience vasomotor symptoms (e.g. hot flushes/ night sweats; Hillard et al., 2017), urogenital discomfort, anxiety, depression and joint aches (Hillard et al., 2017). Note that not all women experience natural menopause, as some women may experience menopause owing to a pathology of the reproductive system before the expected age of cessation of reproductive function, or accelerated surgical menopause owing to procedures such as bilateral oophorectomy, hysterectomy, chemotherapy or GnRH analogues (Hillard et al., 2017).

From an evolutionary standpoint, menopause is often equated with another feature of the female reproductive lifespan - age at last birth. Most evolutionary approaches investigating the origins of menopause focus on the cessation of fertility rather than the cessation of reproductive function per se, especially in non-menstruating species. While reproductive capacity may coincide with age of last birth in other species displaying early reproductive cessation, e.g. the killer whale (Orcinus orca; Cant \& Croft, 2019; Croft et al., 2017), menopause and age at last birth do not always coincide in humans: an individual becomes post-fertile following their last birth, but they are not necessarily post-reproductive if they are still cycling (Figure 1; Levitis, Burger, \& Lackey, 2013). Indeed, the two phases are reached on average 10 years apart in contemporary populations (Towner, Nenko, \& Walton, 2016), and there is only limited correlation between age at last birth and age at menopause (reviewed in Towner et al., 2016). Thus, one cannot assume that the cessation of fertility is dependent solely on physiological reproductive decline. Rather, age at last birth is influenced by sociocultural and biological factors other than reproductive senescence (Bongaarts, 1978), including exposure factors (partner availability), deliberate fertility control factors (family planning, induced abortion) and natural fertility factors (lactational infecundability, frequency of intercourse, pathological sterility, spontaneous intrauterine mortality; Bongaarts, 1978).

The extent to which age at menopause and age at last birth are determined by the same factors is unclear owing to a paucity of studies considering the two traits together and thus whether the same predictive framework should be applied to both age at last birth and age at FMP remains an open question. To address this gap, in the remainder of this paper, we focus on age at natural menopause, i.e. the age at FMP, rather than age at last birth.

\section{Human variation in age at natural menopause}

Self-reported age at menopause is variable, with mean age throughout the twentieth century being anywhere between 44.6 and 54.5 years of age across different geographical regions (Laisk et al., 2018), and between 46 and 51.7 years of age in studies conducted between 1990 and 2010 (Figure 2). Temporal changes in age at FMP occur across different birth cohorts, with a cohort 


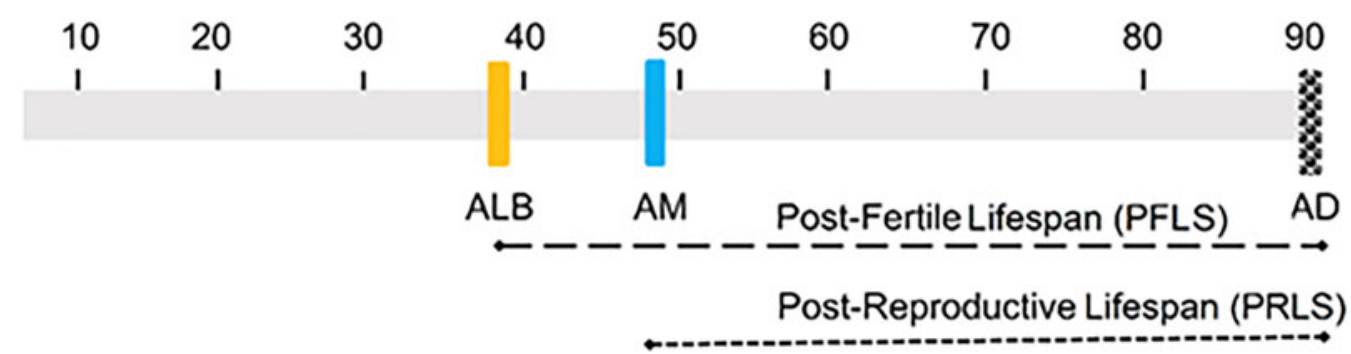

Figure 1. Measuring post-reproductive lifespan: the differences between post-fertile lifespan (PFLS) and post-reproductive lifespan (PRLS). ALB, Age at last birth; AM, age at menopause; AD, age at death. Post-fertile lifespan is defined as the length of time between age at last birth, which typically occurs between 39 and 41 years (reviewed in Towner, Nenko, \& Walton, 2016) and age at death. In contrast, post-reproductive lifespan is defined as the length of time between age at menopause and age at death. Reproductive senescence corresponds to fertility decline over age, which culminates in the age at menopause (AM). Note that this is not the same as age at last birth. Arguments regarding the evolution of menopause - focusing on age at last birth - may not hold for explaining diversity in the timing of menopause.
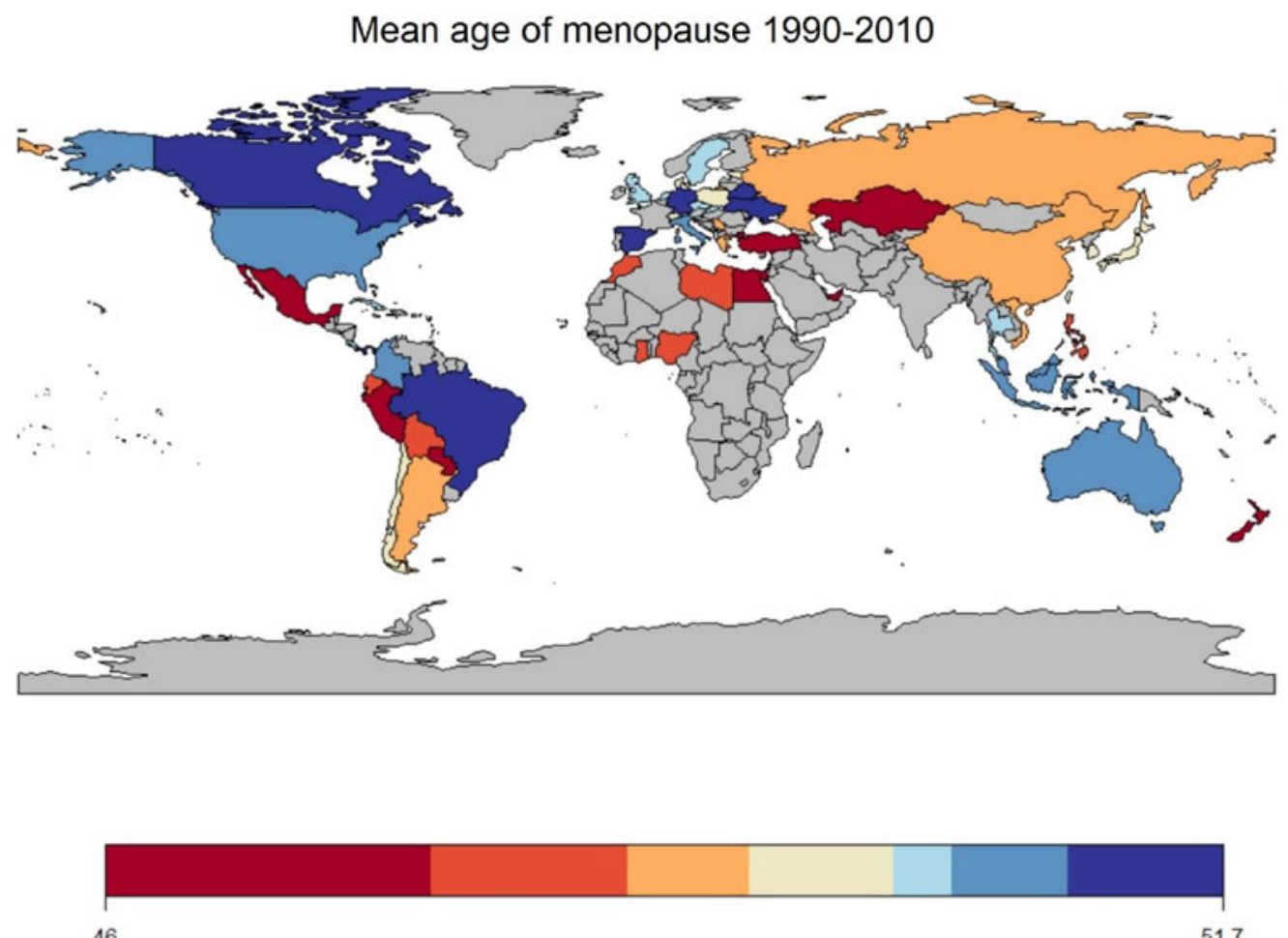

Figure 2. Variation in final menstrual period (FMP). This map was replicated from Laisk et al. (2018), with additional segregation of data based on the decade in which it was collected. Variation in self-reported mean age at FMP is measured between 1990 and 2010 across countries. Broadly, mean age of menopause is higher in the Global North than in the Global South, but owing to the lack of measurement of age at menopause across populations, there is a sizeable uncertainty associated with this pattern. Additionally, the measurement of age at menopause in the studies included here may also be subject to limitations (discussed in Box 1). See Supplementary Information for references, sample sizes and years during which the data were collected.

study in Sweden identifying a 1 month increase of menopausal age with each year of birth (Rodstrom et al., 2003). While there seems to be significant variation worldwide in age at menopause, the data underpinning this picture are somewhat problematic owing to methodological considerations, including an overrepresentation of clinical based studies in the global North, debatable inclusion/exclusion 
Box 1: Methodological considerations when measuring age at menopause

Advancing knowledge of current patterns of diversity in menopause timing requires population-based studies to be conducted outside the Global North. In addition, there are several limitations to both measuring menopause (e.g. age at FMP) within populations and interpreting the results. Those issues, listed below, should be addressed in future studies:

(i) The measurement of FMP may only be confirmed retrospectively. This increases the difficulty of recruiting women who are newly post-menopausal for cross-sectional studies. Additionally, many current cohort studies use the midpoint between two cohort waves where menstruation is present and then absent as age at FMP. Such data are then often analyzed using discrete categories or 'binning' (eg. <45, 46-50, 51-55, 56+), which may obscure any smaller trends in age at menopause.

(ii) A woman's true age at menopause may be masked pharmaceutically (FSRH, 2017; Hillard et al., 2017).

(a) If a woman is taking combined oral contraceptives or hormone replacement therapy, bleeds are not menstrual cycles but rather withdrawal bleeds under the control of medication (FSRH, 2017). Prescription guidelines advise a change away from combined oral contraceptives to a progesterone-based contraceptive over the age of 50 (or 35 for smokers or people with other risk factors; Hillard et al., 2017), given the high risk of thromboembolism (FSRH, 2017). After this, bleeding may stop, and the individual may be considered post-menopausal. However, any bleeding experienced while on oral contraception is a withdrawal bleed, and a woman's reproductive capacity may have ceased prior to stopping oral contraceptive usage.

(b) Similarly, the use of combined hormone replacement therapy (HRT) during the peri-menopausal stage can also produce withdrawal bleeds (Hillard et al., 2017). These examples highlight the importance of defining menopause as the cessation of menstrual cycles, rather than all forms of bleeding, as bleeding can also originate from the use of hormonal contraceptives and HRT.

(c) If a woman is using progesterone-only contraceptive methods, age at menopause may also be masked by amenorrhoea produced by contraceptive usage. This is potentially a frequent issue: the chance of amenorrheoa by 12 months using the Mirena/levonorgestrel releasing intra-uterine system (the hormonal coil) is $20-80 \%$, and this form of contraception has the highest continuation rates in women aged $39-48$ (Currie, 2019).

These examples highlight the importance of defining menopause as the cessation of menstrual cycles, rather than all forms of bleeding, as bleeding can also originate from the use of hormonal contraceptives and HRT.

(iii) A woman's true age at menopause can be difficult to identify. It is possible that during peri-menopause a woman may not have a period in 12 months, then experience bleeding. The irregularity of menstrual cycles may result in periods longer than 12 months where a woman appears to be anovulatory, especially towards the later peri-menopause when menstrual cycles tend to be longer (Harlow \& Paramsothy, 2011). While this bleeding may be considered a period, it may not be a menstrual cycle but the result of reproductive malignancies which can occur in the post-menopausal body (Hillard et al., 2017). Furthermore, menstrual cyclicity amongst women is often more variable than a consistent 28 day cycle throughout reproductive life (Gorrindo et al., 2007; Kato et al., 1999). This is especially pertinent amongst contemporary natural fertility populations where menstrual cycles may be much less frequent than in contemporary Western populations (Strassmann, 1997).

(iv) There is no clinical diagnostic tool able to discern menopausal status through measuring hormone levels. While follicle-stimulating hormone (FSH) levels may be diagnostic for cases of early menopause $(<45), \mathrm{FSH}$ levels are unreliable for assessing menopausal status owing to fluctuations in levels throughout peri-menopause (FSRH, 2017; NCC-WCH, 2015). Additionally, levels of the anti-mullerian hormone (AMH), even in multiple assessments, are unreliable for measuring ovarian reserve, owing to the wide variation in levels of AMH within populations, as well as lack of a uniform AMH decline (de Kat et al., 2017).

criteria, data binning bias and cross-cultural bias (Box 1). Thus, much of the literature reviewed in this paper is only approximating global variation in menopause timing.

Epidemiological studies, for the most part conducted in high-income countries and based on clinical rather than population-based samples, shed some light on the macro-level determinants of menopause timing. First, genetic contribution to age at menopause appears modest: GWAS-identified loci only explain $2.5-4.1 \%$ of population variation in menopause timing (Stolk et al., 2012), suggesting that genetic diversity holds little explanatory power for understanding diversity in age at menopause (but see Section 3 on the genetics of longevity). Other studies identified mixed associations between menopausal age and reproductive life history, socioeconomic status and lifestyle factors. For instance, early 
age at menopause has been associated with early menarche (G. D. Mishra et al., 2017; Ruth et al., 2016) and nulliparity (Duarte, de Sousa, Cadarso-Suarez, Rodrigues, \& Kneib, 2014; G. D. Mishra et al., 2017), while increasing parity (number of pregnancies) is associated with later age at menopause (Duarte et al., 2014; Gold et al., 2001; G. Mishra, Hardy, \& Kuh, 2007; G. D. Mishra et al., 2017). Various markers of lower socioeconomic status or indicators of stress both in early life (household crowding; father's social class; parental divorce, poor cognitive ability, maternal smoking; perception of being thin; R. Hardy \& Kuh, 2005; G. Mishra et al., 2007; Ruth et al., 2016) and in later life (educational status, regional purchasing power; Duarte et al., 2014; Schoenaker, Jackson, Rowlands, \& Mishra, 2014) are associated with an earlier age at menopause. Those relationships are not mediated by the correlation between age at menarche and poor early life conditions given that most studies control for age at menarche (Schoenaker et al., 2014). Age at menopause is consistently associated with lifestyle factors - smoking has a strong association with earlier age at menopause (Gold et al., 2001, 2013; R. Hardy \& Kuh, 2002; Laisk et al., 2018; Ruth et al., 2016; Schoenaker et al., 2014), while there is a weak association between lower body mass index and earlier age at menopause (Henderson, Bernstein, Henderson, Kolonel, \& Pike, 2008). Whether these different associations are globally salient is unknown, however, given that most epidemiological data are derived from clinical studies conducted in high-income countries.

There is currently no overarching framework for explaining why age at menopause correlates with reproductive, socioeconomic and lifestyle factors. Further, knowledge and theories from physiology, epidemiology and evolutionary ecology are not usually considered together. However, if one is to understand both why and how menopause timing varies, it is necessary to account for determinants at multiple levels. To do this, a human evolutionary ecology approach, drawing on the MayrTinbergen Framework accounting for both ultimate and proximate causes of diversity together, offers a promising avenue (Laland, Sterelny, Odling-Smee, Hoppitt, \& Uller, 2011). In the next section we harness this model by considering both current knowledge of the physiology of menopause (proximate) and current evolutionary theories for the evolution of early reproductive cessation (ultimate) to propose a new understanding of diversity in menopause timing in humans, i.e. the age at FMP.

\section{Integrating ultimate and proximate explanations}

In this section, we seek to answer the ultimate question 'Why does variation in age at natural menopause exist?' together with the proximate question 'How does variation in age at natural menopause occur?' In other words, we aim to integrate proximate understandings of ovarian ageing with evolutionary, historical approaches to menopause timing, which include both adaptationist (i.e. menopause timing has fitness benefits) and by-product (i.e. menopause timing has no fitness benefits) hypotheses (Nesse et al., 2010; Stearns, 2012). Recent studies on menopause timing view age at menopause as a facultative adaptation - i.e. menopausal age varies in response to ecology in a way that maximises fitness (Chan, Gomes, \& Singh, 2020; Galbarczyk \& Jasienska, 2013; Skjaervo \& Roskaft, 2013; Yang, Arnot, \& Mace, 2019). Those studies are generally silent with regards to physiological understandings of ovarian ageing, however. In contrast, the hypothesis viewing human menopause as an evolutionary by-product of the selection for an elongated lifespan is consistent with the finding that ovarian ageing is constrained by somatic processes rather than triggered (Box 2). In this way, the determinants of age of natural menopause may be similar to the genetic, developmental and ecological determinants of somatic ageing.

\section{Physiological understanding of menopause timing (proximate approach)}

At the physiological level, the transition towards menopause is generally understood in terms of the processes of ovarian ageing and follicular atresia - the apoptosis (or programmed cell death) of oocytes (egg cells) (Narkwichean et al., 2017). Ovarian ageing is the process whereby the ovaries decline in their ability to recruit and develop successful oocytes (Wang, Zhang, Jiang, \& Seli, 2017). Ovarian ageing adversely affects female fertility, reducing the probability of successful pregnancy owing to increasingly poor quality of follicles. The follicle is the cellular structure containing both the oocyte and surrounding 
granulosa cells and is recruited during the follicular phase of the menstrual cycle. If the follicle is of low quality, it will undergo atresia - programmed cell death - hypothesised to be under the control of the supporting granulosa cells (Banerjee, Banerjee, Saraswat, Bandyopadhyay, \& Kabir, 2014; Tatone \& Amicarelli, 2013). As the ovary ages, both the quantity and the quality of follicles decreases (J. J. Zhang et al., 2016), a process referred to as follicular depletion. At menarche the number of follicles is approximately 300,000-400,000 and reduces to below 1000 at menopause (Forman, Mangini, Thelus-Jean, \& Hayward, 2013). The ovary loses follicles in two ways: ovulation and follicular atresia. As $\sim 400$ follicles are released through ovulation during the reproductive lifespan, the main source of

Box 2: Germ cells are well protected against ageing forces, but the somatic cells of the follicle are not

Perhaps one central issue to integrating ovarian ageing with somatic processes of ageing is that the oocyte itself is a germ cell. While the oocyte may possess multiple defence mechanisms against ageing, the somatic granulosa cells which surround the oocyte in the follicle are subject to somatic ageing. As the somatic granulosa cells decrease in quality, the quality of the overall follicle (including the oocyte itself) decreases and is at risk of undergoing apoptosis.

Ovarian ageing is often centred on the role of mitochondria, exploring the role of dysregulated respiration in the ageing process. Mitochondria are responsible for the energy production and also producing damaging reactive oxygen species (ROS) and reactive carbonyl species through respiration. Primordial follicles can be kept in a state of arrested prophase for upwards of 50 years and so there is potential during this arrest for damage to accumulate in the oocyte while it is quiescent (Hammond et al., 2016). However, the oocyte itself is well protected against oxidative damage, and it has been suggested that localised antioxidant production around the oocyte offers adaptive protection against DNA damage caused by ROS and during its suspended lifespan (Hammond et al., 2016; D. D. Zhang et al., 2015). Localised production of melatonin in the ovary, which has antioxidant properties, also supports the presence of protective measures in the ovary against the impact of long-term exposure to ROS (Tamura et al., 2017). As such, mitochondrial DNA in the oocyte is not shown to accumulate mutations during ovarian ageing in the way predicted if there were no methods of oxidative shielding (Boucret et al., 2017).

The granulosa cell therefore becomes the locus for attention on processes leading to follicular atresia, as well as the site of increasing genomic instability of ageing oocytes (Banerjee et al., 2014; Boucret et al., 2017; May-Panloup et al., 2016; D. D. Zhang et al., 2015). Follicular atresia is initiated through the granulosa cells, which accompany the oocyte from oogenesis to the creation of the antral follicle. Thus, the process of follicular atresia depends on the quality of the granulosa cells - not the oocytes. The senescence of the somatic cells in the ovarian microenvironment becomes the locus for studying determinants of ovarian ageing (Banerjee et al., 2014; Tatone \& Amicarelli, 2013).

follicle loss during the lifetime is atresia (Forman et al., 2013), with the rate of follicle loss also being influenced by multiple factors. Thus, while menopause is co-produced by ovarian ageing and follicular depletion together, ovarian ageing is constrained by somatic ageing of the follicle (Box 2).

Follicular depletion becomes implicated in determining the age at menopause when depletion causes the number of follicles to be below that required to support menstruation (Leidy, Godfrey, \& Sutherland, 1998). At this point, menstrual cycles become dysregulated and ultimately cease. Conventional understandings of follicular atresia rates have considered the rate to be biphasic with accelerated rates of atresia occurring beyond the age of 35 (Leidy et al., 1998). This, however, is shown to be the result of misinterpreting plots of follicular atresia rates (Leidy et al., 1998). Rather, accelerated rates of follicular atresia tend to occur much later, and are more likely within several years of the onset of menopause (Leidy et al., 1998). This suggests that processes underpinning the process of follicular atresia are key to the transition towards menopause.

The rate of follicular atresia is potentially influenced by the inflammatory profile of the menstrual cycle: ovulation is characterised by inflammation of the ovaries, while menstruation has been deemed a 'massive inflammatory event' (Alvergne \& Högqvist Tabor, 2018). Inflammation is a major determinant of the ageing process because it releases ROS, which are free radicals implicated in the aetiology of many non-communicable diseases through the promotion of cell senescence (Franceschi \& Campisi, 2014). It remains to be investigated how repeated cycles of ovulation and menstruation influence ageing of the granulosa cells and thus follicular atresia. Diversity in cyclical life-history owing to anovulatory cycles, pregnancies or hormonal contraceptives is likely to be important for explaining patterns of reproductive senescence and the onset of menopause. 


\section{Evolutionary understanding of menopause timing (ultimate approach)}

Why menopause timing varies has attracted little research to date (but see (Laisk et al., 2018) for a review), most research focusing on the question of why menopause - defined as the permanent cessation of fertility - exists at all in humans and in some other species. Adaptationist perspectives consider the paradoxical occurrence of fertility cessation to hold an adaptive benefit given females do not directly increase their fitness consistently throughout their adult life. In this framework, menopause - by enabling women to avoid later-life reproduction - reached fixation in humans because it conferred fitness benefits through increased alloparental care and decreased reproductive conflict and mortality risk (Cant \& Johnstone, 2008; Cant, Johnstone, \& Russell, 2009; Croft et al., 2017; Ellison, 2001; Hawkes \& Coxworth, 2013; Hawkes, O'Connell, Jones, Alvarez, \& Charnov, 1998; Kirkwood \& Shanley, 2010; Packer, 2001; Peccei, 2001; Williams, 1957). In contrast, by-product theories view the emergence of menopause as an epiphenomenon - a spandrel (Gould \& Lewontin, 1979) - co-produced by the finite nature of a female's oocyte supply and extended lifespan longevity, which allow females to outlive this supply (Cohen, 2004; Ellison, 2001; Peccei, 2001). In this view, menopause emerged in human females because somatic longevity increased, while reproductive longevity did not. Our purpose here is not to dispute which framework is more salient for understanding the emergence of menopause, as indeed processes underpinning the emergence and the maintenance of traits might differ. Rather, we use those hypotheses as a guiding framework for explaining why age at menopause varies.

Recent research into the timing of menopause has taken an adaptive stance. In this view, menopause is a facultative trait where menopause timing responds to ecological factors such as daughter's reproductive success, dispersal patterns and living in the matrilineal/patrilineal household (Cant \& Johnstone, 2008; Skjaervo \& Roskaft, 2013; Yang et al., 2019). Studies have found little support for modification of menopausal age based on either mediating factor, nor have they given suggestions for physiological mechanisms to explain how age at menopause could be affected by factors such as dispersal and daughter's reproductive success. Additional adaptationist theories, such as the 'shifting mate choice/shifting menopause' hypothesis, posit that variation in age at natural menopause occurs in response to later age of reproduction, through the removal of deleterious alleles selecting for menopause, which have accumulated owing to male preference for younger mates (Chan et al., 2020). Fundamentally, adaptationist perspectives have not proposed or found a genetic or physiological pathway producing a cascade which triggers reproductive senescence during midlife and would allow menopause timing to be facultative.

Comparatively, menopause timing has seldom been explored from the premise that menopause is a by-product of selection on longevity, following the decoupling of somatic and reproductive lifespan in human females. This may be due to the unclear directionality of mechanisms considered to be involved in the decoupling of reproductive and somatic lifespan - a prerequisite for this hypothesis. Female reproductive skew, and the front loading of reproductive events, is invoked as a mechanism that could be the cause of the evolution of menopause as it would decrease selection on extended reproductive lifespan (Peccei, 2001). However, given that the preference for younger females is found in humans (Chan et al., 2020; Takahashi, Singh, \& Stone, 2017), but not particularly in chimpanzees (Takahashi et al., 2017), the human male mate preference is likely a derived trait and may be the outcome, rather than the cause, of early reproductive cessation in women. Nevertheless, the length of the female reproductive lifespan in humans is comparable with that of other species of similar body sizes (Peccei, 2001), while the length of somatic lifespan is not, suggesting that extended longevity is a derived trait in humans, while the length of the reproductive lifespan is not. This raises the possibility that age at menopause (rather than age at last birth) is at least partly determined by processes underpinning somatic ageing. In this line, ageing of the human female reproductive capacity is constrained by somatic ageing of the follicles (Box 2), as measured by the rate of follicular atresia. The somatic cells supporting reproduction age faster than the oocyte and the ovary are because they are less well protected from oxidative damage. Thus, exposure to factors implicated in increasing longevity could increase reproductive lifespan. 


\section{Towards a multilevel framework}

Patterns of diversity in age at menopause are poorly understood. To address this, we propose a multilevel, interdisciplinary framework, combining proximate, physiological understandings of ovarian ageing with ultimate, evolutionary ecological perspectives on ageing. We hypothesise that evolutionary ecological factors known to influence somatic ageing variation (the genetics of longevity, early life environments, infections) can also explain rates of ovarian ageing, follicular depletion and diversity in the onset of menopause.

Overall patterns of ageing and senescence are understood evolutionarily through the Disposable Soma hypothesis (Kirkwood, 1977, 1999), where the body's capacity to accumulate deleterious senescent cells is attributed to declining selection pressure of maintenance mechanisms as age increases, owing to increasing extrinsic mortality risk (Kirkwood, 1999). Through the evolutionary lens, age-related health decline results from accumulated damage and suboptimal functioning of bodily systems on the molecular, cellular and organ levels (Kirkwood, 1999). When menopause becomes conceptualised as the by-product of ageing of the reproductive system, by-product hypotheses of menopause are compatible with current physiological understandings of ageing and cellular senescence. Exploration into variation therefore allows overarching theories of ageing rate variation to be applied to the female reproductive system.

Rates of cellular senescence can vary depending on the interaction between an organism and ecological factors (e.g. food availability, stress, pathogen load), producing patterns of ageing rates which vary within and between populations. Ecological factors might also influence women's cyclical lifehistory, producing diversity in anovulatory cycles, pregnancies or hormonal contraceptives, which are likely to be important for explaining patterns of reproductive senescence and the onset of menopause. These ecological factors will be explored in the next section in relation to current epidemiological understandings of variation in age of natural menopause, and with suggestions for further research.

\section{Understanding patterns of menopause timing}

In this section, we review the role of genetic, environmental and reproductive factors in explaining diversity in somatic senescence rates - ecological interactions which influence somatic ageing. This follows from the previous section where we suggest how these might be applied to understanding diversity in ovarian ageing. We show that there are common genetic factors between extreme longevity and age at menopause with regards to genes mediating metabolic profiles, metabolism and oxidative shielding. Following research showing that the early life environment influences the pace of reproductive development and life-history 'strategy', we hypothesise that poor early life environment may result in lower embodied capital, and thus earlier age at menopause. Finally, we propose that women who experience a higher number of cumulative ovulatory menstrual cycles may experience earlier age at menopause through the cumulative exposure of localised inflammation in the female reproductive organs during ovulation. We show that the phenotype of age at menopause may be the result of an interaction between genetic, ecological factors and the cycling life-history.

\section{Genetic factors}

Genetic factors between ovarian ageing and overall somatic ageing show similarities in the biochemical pathways in which they are implicated. Human longevity is a complex biosocial trait, with genetics being highly context-dependent and rates of senescence resulting from a dynamic process (Giuliani, Garagnani, \& Franceschi, 2018). There are no genes which 'code for' longevity in humans (Giuliani et al., 2018), and associations between alleles and longevity occur where such alleles produce a phenotype conducive for long life, especially amongst centenarians (individuals who have lived to age 100). Such phenotypes include metabolic profiles characterised by preserved glucose tolerance and insulin sensitivity; compressed morbidity and disability in later life, and general avoidance or postponement of age-related diseases; and decreased DNA methylation compared with others of the same chronological age (Giuliani et al., 2018). Such phenotypes are conducive of reduced levels of accumulated 
damage contributing to the functioning of bodily systems on the molecular, cellular and organ levels. These phenotypes may therefore promote both somatic longevity and reproductive longevity, thus postponing age at menopause.

Genetic factors which have been identified as contributing to the phenotype of somatic longevity, reproductive longevity or both include the following:

- APOE: the APOE gene codes for apolipoprotein E, which helps maintain structural integrity and function of cholesterol rich lipoproteins. The protein structure of APOE varies and is found to exist in three different isoforms which alter its function. Isoforms APOEe2, APOEe3 and APOEe4 are positively associated, not associated or negatively associated with longevity, respectively (Abondio et al., 2019). Regarding menopause, association between isoforms and reproductive longevity has been inconclusive. Heterozygous APOEe $3 / 4$ carriers show a delayed age at menopause compared with APOEe3/3 carriers in a Chinese population (Meng et al., 2012). Both APOEe4 and APOEe2 isoforms have been associated with predicted earlier age at menopause amongst Iranian females and women of European descent, respectively (Koochmeshgi, Hosseini-Mazinani, Morteza Seifati, Hosein-Pur-Nobari, \& Teimoori-Toolabi, 2004; Tempfer et al., 2005).

- Sirtuins: Sirtuins are proteins which modulate metabolism, cell proliferation and genome stability. Regulation of several sirtuin genes - SIRT5 and SIRT7 - has been found to have a positive association with longevity, while a minor SIRT6 homologous allele, affecting its function, has been associated with decreased lifespan (Giuliani et al., 2018). Variation in sirtuin regulation has been linked to reproductive longevity, with downregulation of SIRT1, SIRT3 and SIRT6 being linked to an increased rate of ovarian ageing (J. J. Zhang et al., 2016).

- Mitochondrial Haplotype J: Mitochondrial DNA Haplotype J is hypothesised to reduce the output of both ATP (the product of respiration) and ROS. The mtDNA J haplotype has been positively associated with somatic longevity in European populations (Giuliani et al., 2018), and was underrepresented amongst French women with depleted ovarian reserves undergoing fertility treatment (May-Panloup et al., 2014), suggesting it plays a role in reproductive longevity.

- FOXO3: FOXO3 is a gene which downregulates activity on the IGF1 pathway, helping to maintain a metabolomic profile conducive to longevity (Giuliani et al., 2018). Associations between expression of FOXO3 and reproductive longevity are unknown.

- IL6: Modulation of interleukin 6, a multifunctional cytokine associated with inflammatory responses by a minor allele has also been associated with longevity and the aetiology of age-related disease (Giuliani et al., 2018). Associations between IL6 modulation and reproductive longevity are unknown.

Additional single nucleotide polymorphisms associated with age at menopause have been linked to genes involved in hormonal regulation, immune function and DNA repair pathways (Stolk et al., 2012). A candidate gene located on the Human Leukocyte Antigen transcript has been associated with age at menopause as well as Type-1 diabetes and rheumatoid arthritis (Stolk et al., 2012). Such a gene implicates a pro-inflammatory component to physiological pathways mediating rates of ovarian ageing (Stolk et al., 2012). BRCA1 mutations also confer an increased rate of ovarian ageing, hypothesised to be due to increased rates of double-strand DNA breaks in follicles, causing subsequent increase in the rate of follicular atresia (Box 2, Figure 3; Lin, Titus, Moy, Ginsburg, \& Oktay, 2017).

Determinants of longevity and somatic senescence are hugely complex, with genetic factors only explaining a small proportion of variation in longevity (Giuliani et al., 2018). GWAS-identified loci and their related function only explain $2.5-4.1 \%$ of population variation in the age at menopause (Stolk et al., 2012). The genetic contribution to age at menopause, and overall senescence rates may be overpowered by ecological and environmental factors and so must be considered in relation to other exogenous factors. Despite the low contribution genetic variation makes, these studies indicate that processes of non-communicable diseases and ovarian ageing are underpinned by similar metabolic and inflammatory processes. 


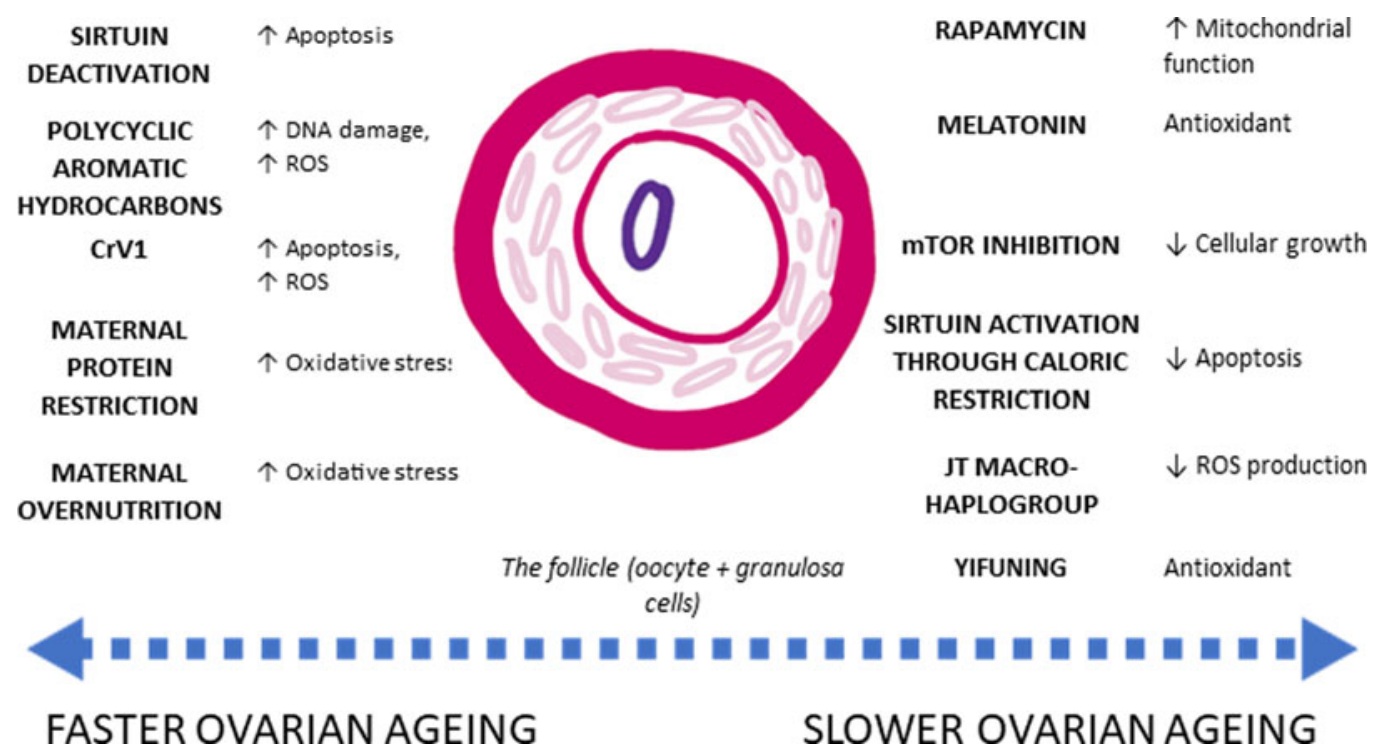

Figure 3. Agents which influence ovarian ageing. Agents with their respective effect on rates of ovarian ageing. ROS (reactive 2oxidative species) produce oxidative stress, which contributes to cellular senescence and cell apoptosis. Conversely, agents which contain antioxidants improve overall mitochondrial function, slowing down the rate of cellular senescence. However, while some physiological processes are known, there has been no ecological study accounting for fast or slow ovarian ageing. Lists of references are provided in the Supporting Information.

\section{Ecological factors}

Rates of age-related health decline are in part mediated by an individual's ability to accrue somatic capital - a factor dependent on environmental constraints on energy available for their growth and development. Somatic capital can be understood as the energetic investments made by the body in growth and maintenance of tissue beds and organs (Kaplan, Lancaster, \& Robson, 2003), which will depreciate over time through wear and tear. As the body's ability to maintain cellular and tissue function decreases over time, mechanisms in the ageing body must rely on their existing somatic capital to ensure optimal function is maintained. Somatic capital accrual can be influenced by the life history strategy of the individual. Life history theory (Ellison, 2003; Gluckman, Beedle, \& Hanson, 2009) broadly describes patterns of growth, reproduction and mortality in an individual's life and in a given environment. One particularly influential concept in life-history evolution is that of the 'fast-slow continuum', which accounts for the fact that many life-history traits co-vary across and within species (Stearns, 1992). Age at menopause may therefore be understood as an outcome of a life-history strategy, itself contingent on the somatic capital of the female reproductive system, determined by ecological factors (e.g. food availability, stress, pathogen load). Using a life history theory approach allows investigating whether variation in age at menopause reflects overall rates of ageing in the body or is specific to reproductive senescence.

\section{Extrinsic mortality}

Life history theory posits that, in environments with high extrinsic mortality (i.e. mortality independent of an individual's phenotype), metabolic investment in reproduction is prioritised at the expense of other fitness components (somatic maintenance, growth; Stearns, 1992). This leads to the acceleration of an organism's life-history (hence a 'fast life-history' strategy; Hidaka \& Boddy, 2016; Nettle, 2010; Stearns, Ackermann, Doebeli, \& Kaiser, 2000) and is hypothesised to affect rates of ageing and the development of age-related diseases. In humans, age at first birth in England is younger in deprived 
areas compared with more affluent areas, which is interpreted as a response to the ecological context of poverty (Nettle, 2010), with girls from moderately stressful environments of nutritional inadequacy experiencing accelerated pubertal timing (Ellis, 2004). In turn, low embodied capital of the reproductive system may cause suboptimal tissue defence (Noguera, 2017) against the oxidative stress of menstruation and reproduction, increasing rates of follicular atresia. This may ultimately accelerate reproductive ageing towards menopause. In comparison, those living in energy-rich, low-mortality environments may accrue higher somatic capital owing to a slower life history strategy (Ellis, 2004). Higher socioeconomic living conditions may therefore be associated with later age at menopause given the prolonged ability for tissue maintenance in those with higher somatic capital.

It is important to clarify at this point that life history strategies are often used in a behavioural context, to explain patterns of behaviour - often related to reproduction (Nettle, 2010). Here, we use life history strategies to refer to the allocation of physiological resources, contributing to the embodied capital of the individual rather than in a more behavioural context.

Fast/slow life history theories as a predictive framework are in line with trends in epidemiological studies where earlier age at menopause is found amongst low/middle-income populations, as well as amongst those who were exposed to poor environmental conditions earlier in life (Duarte et al., 2014; R. Hardy \& Kuh, 2005; G. Mishra et al., 2007; Ruth et al., 2016; Schoenaker et al., 2014). Furthermore, in Western populations, earlier age at menopause has been associated with an increased risk of cardiovascular diseases (CVD), atherosclerosis, stroke and osteoporosis (Forman et al., 2013; Schoenaker et al., 2014) while later menopause has been associated with both a reduced risk of CVD and all-cause mortality and an increased risk of breast and ovarian cancer and osteoporosis (Forman et al., 2013; Henderson et al., 2008; Ossewaarde et al., 2005; Schoenaker et al., 2014). Finally, studies into oestrogen-receptor negative breast cancer rates suggest that a fast life history strategy may result in a higher incidence of breast cancer amongst women of lower socioeconomic status (Hidaka \& Boddy, 2016).

\section{Infectious diseases}

Additional metabolic trade-offs between growth, maintenance and reproduction can occur in the presence of infectious disease where energy is allocated to the immune system at the expense of other bodily functions (Ellison, 2003). Sievert has previously explored the relationship between age at menopause and exposure to infectious diseases over the life course amongst Bangladeshi women living in London. They were found to have a significantly earlier age at menopause than other women living in London, with earlier age being strongly associated with a history of infectious disease exposure on multiple occasions (Sievert, 2014). As immune defences against pathogens are energetically costly, pathogen load may also contribute towards reducing bodily investment in the growth and maintenance of the body. Studies researching the effect of prolonged infection on age at menopause show a younger age at menopause amongst women with HIV compared with women without HIV in the Bronx (Schoenbaum et al., 2005), although this result is not entirely consistent (Conde, Pinto-Neto, \& Costa-Paiva, 2008). There is potential for expanding research into the influence of infectious diseases on age at menopause by studying (a) the impact of infections earlier versus later in life, (b) populationlevel patterns where malaria is endemic and (c) and immunocompromised populations.

\section{Cyclical reproductive life history}

Variation in rates of ovarian ageing may result from the cumulative exposure of the female reproductive system to cyclical inflammation, which may vary across ecologies. Reproduction in human females is characterised by cyclical fertility, with menstrual cycles completed between approximately 24 and 38 days (Alvergne \& Högqvist Tabor, 2018), with the end of non-conceptive cycles characterised by menstruation, a massive inflammatory event. Localised inflammation also occurs in the ovaries during the inflammation-mediated repair of the corpus luteum immediately after ovulation (Alvergne \& Högqvist 
Tabor, 2018). Furthermore, the ovaries are the site of oestrogen production - hormones which can act as pro-inflammatory, depending on dose. Through menstrual cycling, cyclical, systematic inflammation may contribute to damage of the granulosa cells and ovarian microenvironment, resulting primarily in the accelerated senescence of the female reproductive function relative to other organs of the body.

There is some evidence that ovarian ageing rates may vary according to the total number of menstrual cycles experienced in a female's reproductive lifespan. First, high cumulative levels of oestrogen exposure are known to be a risk factor for the development of oestrogen receptor-positive breast, ovarian and endometrial cancers (Aktipis, Ellis, Nishimura, \& Hiatt, 2014; Jasienska, Bribiescas, et al., 2017; Jasienska, Sherry, Holmes, \& SpringerLink, 2017; Strassmann, 1999). Given tumorigenesis also operates through cellular damage and mutations, it is not implausible to consider the effect of concentrated cumulative oestrogen exposure on cellular senescence of the reproductive organs. Second, preliminary epidemiological data show that nulliparity (as a discrete entity) is significantly associated with earlier ages of menopause (Duarte et al., 2014; G. D. Mishra et al., 2017). Normally cycling nulliparous women who are not taking any form of hormonal contraception do not experience the gaps in ovulation that occur during the gestation period and breastfeeding. This suggests that the female reproductive life history should be considered in its entirety - e.g. as total number of menstrual cycles experienced - rather than as a composite of discrete entities (e.g. age at menarche, parity, breastfeeding and use of hormonal contraception) as it is often approached within epidemiological studies. This approach has already been used in several epidemiological studies of breast cancer, where higher numbers of cumulative menstrual cycles have been associated with an increased risk of breast cancer (Chavez-MacGregor et al., 2005; Clavel-Chapelon \& Grp, 2002; Rautalahti et al., 1993).

How ecology influences a woman's cumulative exposure to cyclical inflammation is poorly understood. A 1994 study estimate that women in contemporary Western populations experience up to 400 cycles during the lifetime, compared with a median of 94 within a contemporary natural fertility population (Strassmann, 1997). In the absence of data on the cycling life-history, reproductive traits across the lifespan could be used as a proxy to estimate a woman's cumulative exposure to inflammatory menstrual cycles. Note that ideally, it is the number of ovulatory, as opposed to anovulatory, cycles that is the most relevant measure. Proximate determinants of the number of menstrual cycles might themselves be the outcome of life history strategies explored earlier (see Ellis, 2004), but similar life-history 'strategies' may have different impacts on the number of menstrual cycles depending on sociocultural contexts (i.e. availability of contraception, norms around breastfeeding etc.; Ellis, 2004), although these life-history strategies are not necessarily prescriptive (Nepomnaschy, Rowlands, Costa, \& Salvante, 2020; Sheppard \& Van Winkle, 2020). Nevertheless, life-history and reproductive cyclicity approaches are not mutually exclusive.

Accounting for the cost of cumulative menstrual cycles may have implications for evolutionary models. First, it adds nuance to what may count as a 'cost of reproduction' - this is often referred to as the impact of reproduction and pregnancy on the female body, at the expense of physiological functioning (Ryan et al., 2018). While pregnancy may incur a physiological cost to somatic functioning (Ryan et al., 2018), it may also be protective over ovarian function with regards to the onset of menopause (Duarte et al., 2014; G. D. Mishra et al., 2017). Thus, cyclical menstruation and pregnancy may be better considered as separate entities rather than falling under the all-encompassing 'cost of reproduction'. Second, given the physiological processes of reproductive and somatic ageing are physiologically similar, reproduction might entail costs not only for somatic senescence, a trade-off often studied by evolutionary biologists (see T. B. L. Kirkwood \& Westendorp, 2001), but also for reproductive senescence. While cyclical inflammation confers fitness benefits early in life, more frequent cyclical ovulation in humans might directly influence the onset of menopause through the antagonistic pleiotropic effects of cyclical inflammation.

In this section, we have explored possible evolutionary ecological determinants of diversity in menopause timing. While much of the literature in this review comes from studies in high-income countries, the framework we have developed here may help formulate hypotheses for studies of populations in lower-income countries. Future research investigating how factors such as socioeconomic status, poverty, 
food insecurity and infectious diseases interact with life history and cyclical reproductive life histories may help expand understandings of variation in age of natural menopause within different populations.

\section{Implications for public health}

As ageing populations are perceived to present challenges to the maintenance of population health, healthcare provision, demographic structure and society, there is increasing importance placed on research aiming to understand and predict patterns of ageing (USC Programme on Global Ageing \& Policy, 2018). However, current public health approaches towards understanding diversity in the experience of menopause (age and symptoms) and its impact on health and overall wellbeing are scarce. Here we show that an ecological approach to variation in menopause might help with (a) nuancing assumptions about the 'normal' menopause, (b) understanding the relationship between menopause and health decline, (c) interrogating whether earlier menopause and diseases of old age originate from the same ecological determinants of health and (d) how understanding variation in menopause experience can benefit wider studies into successful ageing.

\section{Stimulating public health research into the diversity of menopausal experience}

Despite a substantial focus within public health on ageing (Beard \& Bloom, 2015), menopause as a facet of the female ageing experience is often excluded from research questions into ageing and subsequent public health interventions (e.g. breast cancer screening). For instance, out of the 15 ageing cohort studies found on the Gateway to Global Ageing Data (USC Programme on Global Ageing \& Policy, 2018), a harmonised dataset aiming at providing resources to support cross-national research on ageing, only five studies collected any form of data on menopause from their female participants. The questions and cohort studies which did include menopause-related variables are found in Table 1 . The observation that menopause is excluded from ageing cohort studies, which premise themselves on collecting data on the multifactorial nature of the ageing experience, reveals the absence of menopause from public health discourses of ageing, which suggests that its impact on the ageing experience is neglected. Any relationships existing between menopause and health are unable to be identified, allowing prevalent biomedical assumptions to prevail. Ignorance of menopause as a facet of female ageing creates a measurement trap, in which lack of information is both the cause and the effect of continuing exclusion (Graham, 1998).

Since the 1990s, several longitudinal studies have been started, many with the specific aim of understanding the impact of HRT usage on later life health among post-menopausal women such as the Women's Health Initiative (Nabel, 2013; Rossouw, Anderson, \& Oberman, 2003) and Million Women Study (The Million Women Study Collaborative, 1999). Study of Women's Health Across the Nation and the International Collaboration for a Life Course Approach to Reproductive Health and Chronic Disease Events are currently collecting and synthetising health data on peri- and postmenopausal women. Inclusion of questions around the menopausal experience in ageing cohort studies, and expansion of menopause-related research questions beyond HRT and later-life health outcomes, will help to corroborate the data collected by the Study of Women's Health Across the Nation and International Collaboration for a Life Course Approach to Reproductive Health and Chronic Disease Events and improve the robustness of research into menopause.

\section{Reframing the menopausal transition as normal}

Understanding menopausal variation can help alleviate the assumptions still present within the biomedical approaches of menopause. Biomedical perspectives of menopause were for most of the twentieth century predicated on the assumption that menopause and the oestrogen-deficient body were inherently 'risky' (Harding, 1997; Lock, 1993), with this risk to be countered through the prescription of HRT during the post-menopausal life stage. While the Women's Health Initiative and Million Women Study revealed the health risks associated with indiscriminate long-term prescription of HRT (to the extent that the experimental studies had to be prematurely ended; Nabel, 2013), assumptions surrounding 
Table 1. Menopause-related variables in the Gateway to Global Aging Data, produced by the USC Program on Global Aging, Health \& Policy, with funding from the National Institute on Aging

\begin{tabular}{|c|c|c|c|}
\hline Cohort & Region & Years & Variables \\
\hline \multirow[t]{3}{*}{ TILDA } & \multirow[t]{3}{*}{ Ireland } & Pilot & \multirow{3}{*}{$\begin{array}{l}\text { Gone through menopause; } \\
\text { age menopause started; } \\
\text { taken prescription hormones; } \\
\text { Number of years taking hormones; } \\
\text { number of years took prescription } \\
\text { hormones }\end{array}$} \\
\hline & & 2010 & \\
\hline & & 2012 & \\
\hline \multirow[t]{2}{*}{ NICOLA } & \multirow[t]{2}{*}{ Northern Ireland } & 2015 & $\begin{array}{l}\text { Gone through menopause; } \\
\text { age menopause started; } \\
\text { used prescription hormones; } \\
\text { number of years taking hormones; } \\
\text { number of years took hormones }\end{array}$ \\
\hline & & 2017 & $\begin{array}{l}\text { Used hormones since menopause; } \\
\text { still using/stopped using hormones; } \\
\text { number of years taking hormones; } \\
\text { number of years took hormones }\end{array}$ \\
\hline \multirow[t]{5}{*}{ HRS } & \multirow[t]{5}{*}{ USA } & 2008 & \multirow{4}{*}{$\begin{array}{l}\text { Current stage of menopause; } \\
\text { how old when finished menopause } \\
(>40,>45,>55)\end{array}$} \\
\hline & & 2010 & \\
\hline & & 2012 & \\
\hline & & 2014 & \\
\hline & & 2016 & $\begin{array}{l}\text { Current stage of menopause; } \\
\text { how oldwhenfinished menopause; } \\
\text { year finished menopause }\end{array}$ \\
\hline \multirow[t]{3}{*}{ CHARLS } & \multirow[t]{3}{*}{ China } & 2011 & \multirow{2}{*}{$\begin{array}{l}\text { Age at menarche; } \\
\text { has menopause started? }\end{array}$} \\
\hline & & 2013 & \\
\hline & & 2015 & $\begin{array}{l}\text { age at menarche; } \\
\text { has menopause started?; } \\
\text { age at menopause }\end{array}$ \\
\hline \multirow[t]{2}{*}{ CRELES } & \multirow[t]{2}{*}{ Costa Rica } & 2005 & \multirow{2}{*}{$\begin{array}{l}\text { age at menarche; } \\
\text { age at last menstruation; } \\
\text { ever used HRT to treat menopause for } 3+\text { years }\end{array}$} \\
\hline & & 2010 & \\
\hline
\end{tabular}

the causality of post-menopausal health issues as well as a lack of recognition of menopause experience variation may arguably still persist within Western biomedicine and public health.

Further, public health research into menopause variation can primarily help nuance the designation of the menopausal transition as 'normal' or 'pathological'. Current UK guidelines state that any woman entering menopause at age $<40$ is experiencing premature ovarian insufficiency while those entering menopause at age $<45$ are experiencing early menopause (NCC-WCH, 2015). As there is little consensus on hormonal diagnosis of ovarian ageing (Box 1) and given that variation in age at menopause exists within and between populations, normal 'earlier' menopause in some women may be accidentally pathologised, while abnormal but 'later' menopause may remain undiagnosed in others. Current biomedical understandings of 'normal' menopause are predicated on normative views of how a 'normal' body should behave (Wiley \& Cullin, 2020). Gathering data to explore the true variation of menopausal age within and between populations will allow this assumption to be challenged.

\section{Rethinking menopause as the by-product rather than the catalyst of biological ageing}

Age at menopause is associated with varying health outcomes, with earlier age at menopause being generally associated with increasing risk of all-cause mortality (Forman et al., 2013; Schoenaker et al., 2014). 
Thus, age at menopause can be used to identify at-risk groups of older women, who could then be targeted with preventative screening programmes and treatment against associated diseases such as cancers, CVD and osteoporosis prior to any manifestation of disease. However, risk factors for health and disease that accelerate biological ageing may also contribute to earlier age at menopause rather than menopause itself being the catalyst for biological ageing (Levine et al., 2016). For instance, menopause has been associated with epigenetic processes linked to cellular senescence and ageing when epigenetic biomarkers of methylation are compared with chronological age (Levine et al., 2016; USA \& European populations, $n=3110$ ). The epigenetic age at blood was found to have a negative correlation with age at menopause, which supports observational studies that found that for every one-year increase in age at menopause, the age-adjusted mortality rate decreases by $2 \%$ (Levine et al., 2016). In this study, there is a suggestion of directionality, with post-menopausal women who had late onset of menopause found to be epigenetically younger than women with early onset menopause. However, risk factors for health and disease that accelerate biological ageing may also contribute to earlier age at menopause rather than menopause itself being the catalyst for biological ageing (Levine et al., 2016). Such research nuances prevailing assumptions around menopause being the cause or catalyst of poor health and disease in later life.

Contrasting with contemporary biomedical perspectives, an ecological approach to understanding diversity in the onset of menopause may show that correlations between earlier menopause and diseases of old age originate from the same life history determinants of health, encompassing somatic capital and life history strategies and the wider sociocultural determinants of health. Such life course studies would fall into the emergent discipline of evolutionary public health (Wells, Nesse, Sear, Johnstone, \& Stearns, 2017), where both proximate and ultimate explanations into patterns of population health and disease are considered within the theoretical framework (Wells et al., 2017). An understanding of how ecological and evolutionary contexts throughout life can help explain patterns of health in older age within and between socioeconomic strata, owing to developmentally and environmentally determined patterns of energy allocation (Wells et al., 2017). Evolutionary public health allows the integration of menopause timing within overarching understandings of ageing and senescence in life history as well as its inclusion in public health data collection and approaches to ageing. This is not to say that menopause has no adverse impact on the health of ageing females, but its insertion into large-scale health data collection would allow any risk factors emerging from menopause to be identified and nuanced, combating the pathologisation of menopause as a whole.

Aside from evolutionary ecological approaches to menopause, there is also scope for integrating menopause into the wider evolutionary medicine paradigm. Reconceptualising health, from an evolutionary perspective, as a means to an end of reproductive success (Wells et al., 2017) requires the recognition that reproductive function is intrinsically intertwined with 'non-reproductive' health. The peri- and post-menopausal body can be reconceptualised as the female body with minimal interaction between the reproductive system and other bodily systems. In doing so, there is incentive to study how the dysregulation and cessation of the menstrual cycle may impact the immune system (for review see Alvergne \& Högqvist Tabor, 2018), or the aetiologies of non-communicable diseases.

\section{Diversity in menopausal experience and the capacity for successful ageing}

While the study of variation may be useful in understanding disease risk, it may be equally important to consider how and why variation in age and experience affects an individual's capacity for 'successful' ageing (Rowe \& Kahn, 2015). There is an increasing awareness of 'successful ageing' in Public Health and Gerontology, which encompasses the social, cultural and psychological impact of growing older beyond the increasing health risks. In this view, the ageing experience is expanded beyond the disease risk and frailty to include facets of the ageing experience that are more important to the individual (Rowe \& Kahn, 2015). Therefore, approaches to menopause as a component of female ageing should also be expanded beyond focusing on health risks.

Facets of the menopausal experience and wider female ageing are already being studied and could benefit from taking the existence of variation into account. This includes areas such as: menopause in 
the workplace (C. Hardy, 2019); grandmothering, its impact on familial health and how menopause may affect the ability to alloparent (Sear, 2016); female personhood during the life course (Pickard, 2019); menopause and sexuality; and more critical medical anthropological perspectives on menopause, biopower and pharmaceutical intervention (Harding, 1997; Padamsee, 2011). Expanding focus onto how diversity in the experience of menopause impacts the wider social and cultural experience of growing older will improve the robustness of public health perspectives on women's ageing, closer to actual lived experience.

\section{Conclusion}

The goal of this paper is to stimulate an interdisciplinary, multilevel framework for understanding the role of evolutionary and ecological factors in shaping diversity in age at natural menopause. By engaging with the definitions of menopause across disciplines, we can ensure that proximate and ultimate approaches to menopause are addressing the same phenomenon, i.e. the cessation of menstrual cycles, rather than broader features of the post-fertile lifespan. We have shown the compatibility of biomedical, physiological understandings of ovarian ageing with evolutionary theories viewing the emergence of menopause as a by-product of recent increases in longevity (e.g. the reproductive-somatic mismatch hypothesis; Cohen, 2004). This suggests that evolutionary hypotheses usually applied to somatic senescence (e.g. the Disposable Soma hypothesis, the antagonistic pleiotropy hypothesis, the embodied-capital theory) may also become fruitful for understanding patterns of diversity in menopausal traits.

A consistent theme throughout this paper has been to highlight potential areas where menopause research is lacking, and which can be expanded both in the medical sciences and in human ecological studies. We also suggest potential implications for approaches towards ageing women's health in public health and the wider medical sciences. We suggest that menopause is currently excluded from public health approaches to ageing and that its continued exclusion cannot be justified. Not only should menopause be measured in ageing cohort studies, but its measurement should be done with the methodological considerations outlined earlier in mind. We also posit that recognition of variation in menopause may help nuance assumptions surrounding normalcy and the menopause, and the clinical cut-offs made between 'normal' and 'abnormal' menopause. We further recognise that through the application of evolutionary theories of ageing towards menopause variation there is an opportunity to reconceptualise menopause as a process of ageing, rather than its cause. This might stimulate novel research questions into which processes underlay both reproductive and overall senescence. This also stands in contrast to the social construction of menopause as a pathology within Western biomedicine, and reaffirms the menopausal transition as normal, rather than inherently pathological.

Supplementary material. To view supplementary material for this article, please visit https://doi.org/10.1017/ehs.2020.59

Acknowledgements. EW is funded by the Medical Research Council (MC_UU_12017/13) and the Chief Scientist Office, Scottish Government (SPHSU13). We thank Gabriella Kountourides and Rose Stevens, members of the Applied Evolutionary Anthropology Group at Oxford Anthropology, for providing useful feedbacks on the manuscript.

Author contributions. Article written by AF, with editing, feedback and guidance from AA, EW and CJ.

Financial support. EW is funded by the Medical Research Council (MC_UU_12017/13) and the Chief Scientist Office, Scottish Government (SPHSU13).

Conflict of interest. AA is on the editorial board of Evolutionary Human Sciences.

Research transparency and reproducibility. Data used to produce Figure 2 available in Supplementary Information. $\mathrm{R}$ code used to produce Figure 2 available upon request.

\section{References}

Abondio, P., Sazzini, M., Garagnani, P., Boattini, A., Monti, D., Franceschi, C., ... Giuliani, C. (2019). The genetic variability of $A P O E$ in different human populations and its implications for longevity. Genes (Basel), 10(3). doi:10.3390/ genes 10030222 
Aktipis, C. A., Ellis, B. J., Nishimura, K. K., \& Hiatt, R. A. (2014). Modern reproductive patterns associated with estrogen receptor positive but not negative breast cancer susceptibility. Evolution, Medicine, and Public Health, $2015(1), 52$. doi:10.1093/emph/eou028

Alvergne, A., \& Högqvist Tabor, V. (2018). Is female health cyclical? Evolutionary perspectives on menstruation. Trends in Ecology \& Evolution, 33(6), 399. doi:10.1016/j.tree.2018.03.006

Banerjee, S., Banerjee, S., Saraswat, G., Bandyopadhyay, S. A., \& Kabir, S. N. (2014). Female reproductive aging is masterplanned at the level of ovary. PLoS One, 9(5). doi:10.1371/journal.pone.0096210

Beard, J. R., \& Bloom, D. E. (2015). Towards a comprehensive public health response to population ageing. The Lancet, 385 (9968), 658. doi:10.1016/s0140-6736(14)61461-6

Bongaarts, J. (1978). A framework for analyzing the proximate determinants of fertility. Population and Development Review, 4(1), 105-132. doi:10.2307/1972149

Boucret, L., Bris, C., Seegers, V., Goudenege, D., Desquiret-Dumas, V., Domin-Bernhard, M., ... May-Panloup, P. (2017). Deep sequencing shows that oocytes are not prone to accumulate mtDNA heteroplasmic mutations during ovarian ageing. Human Reproduction, 32(10), 2101-2109. doi:10.1093/humrep/dex268

Cant, M. A., \& Croft, D. P. (2019). Life-History evolution: Grandmothering in space and time. Current Biology, 29(6), R215R218. doi:10.1016/j.cub.2019.02.012

Cant, M. A., \& Johnstone, R. A. (2008). Reproductive conflict and the separation of reproductive generations in humans. Proceedings of the National Academy of Sciences, 105(14), 5332. doi:10.1073/pnas.0711911105

Cant, M. A., Johnstone, R. A., \& Russell, A. F. (2009). Reproductive conflict and the evolution of menopause. In R. Hager \& C. B. Jones (Eds.), Reproductive skew in vertebrates: Proximate and ultimate causes (pp. 24-50). Cambridge: Cambridge University Press.

Chan, S., Gomes, A., \& Singh, R. S. (2020). Is menopause still evolving? Evidence from a longitudinal study of multiethnic populations and its relevance to women's health. BMC Womens Health, 20(1). doi:10.1186/s12905-020-00932-8

Chavez-MacGregor, M., Elias, S. G., Onland-Moret, N. C., van der Schouw, Y. T., Van Gils, C. H., Monninkhof, E., ... Peeters, P. H. M. (2005). Postmenopausal breast cancer risk and cumulative number of menstrual cycles. Cancer Epidemiology Biomarkers \& Prevention, 14(4), 799-804. doi:10.1158/1055-9965.epi-04-0465

Clavel-Chapelon, F., \& Grp, E. N. (2002). Cumulative number of menstrual cycles and breast cancer risk: Results from the E3N cohort study of French women. Cancer Causes \& Control, 13(9), 831-838. doi:Doi 10.1023/A:1020684821837

Cohen, A. A. (2004). Female post-reproductive lifespan: A general mammalian trait. Biological Reviews, 79(4), 733-750. doi:10.1017/s1464793103006432

Conde, D. M., Pinto-Neto, A. M., \& Costa-Paiva, L. (2008). Age at menopause of HIV-infected women: A review. Gynecological Endocrinology, 24(2), 84-86. doi:10.1080/09513590701806870

Croft, D. P., Johnstone, R. A., Ellis, S., Nattrass, S., Franks, D. W., Brent, L. J., ... Cant, M. A. (2017). Reproductive conflict and the evolution of menopause in killer whales. Current Biology, 27(2), 298-304. doi:10.1016/j.cub.2016.12.015

Currie, H. (2019). The perimenopause: Presentation and management. Paper presented at the Women's Health Concern Annual Symposium 2019, Marylebone, London.

de Kat, A. C., Dam, V., Onland-Moret, N. C., Eijkemans, M. J., Broekmans, F. J., \& van der Schouw, Y. T. (2017). Unraveling the associations of age and menopause with cardiovascular risk factors in a large population-based study. [Erratum appears in BMC Medicine 2017 Mar 29;15(1):74; PMID: 28356103.] BMC Medicine, 15(1), 2.

Duarte, E., de Sousa, B., Cadarso-Suarez, C., Rodrigues, V., \& Kneib, T. (2014). Structured additive regression modeling of age of menarche and menopause in a breast cancer screening program. Biometrical Journal, 56(3), 416-427.

Ellis, B. J. (2004). Timing of pubertal maturation in girls: An integrated life history approach. Psychological Bulletin, 130(6), 920-958. doi:10.1037/0033-2909.130.6.920

Ellison, P. T. (2001). Reproductive ecology and human evolution. New York: Aldine Transaction.

Ellison, P. T. (2003). Energetics and reproductive effort. American Journal of Human Biology, 15(3), 342.

Forman, M. R., Mangini, L. D., Thelus-Jean, R., \& Hayward, M. D. (2013). Life-course origins of the ages at menarche and menopause. Adolescent health, medicine and Therapeutics, 4, 1-21. doi:10.2147/AHMT.S15946

Franceschi, C., \& Campisi, J. (2014). Chronic inflammation (inflammaging) and its potential contribution to age-associated diseases. Journals of Gerontology Series A: Biomedical Sciences and Medical Sciences, 69, S4. doi:10.1093/gerona/glu057

FSRH (2017). FSRH clinical guideline: Contraception for women aged over 40 years. Retrieved from https://www.fsrh.org/ standards-and-guidance/documents/fsrh-guidance-contraception-for-women-aged-over-40-years-2017/

Galbarczyk, A., \& Jasienska, G. (2013). Timing of natural menopause covaries with timing of birth of a first daughter: Evidence for a mother-daughter evolutionary contract? Homo-Journal of Comparative Human Biology, 64(3), 228-232. doi:10.1016/j.jchb.2013.03.004

Giuliani, C., Garagnani, P., \& Franceschi, C. (2018). Genetics of human longevity within an eco-evolutionary nature-nurture framework. Circulation Research, 123(7), 745-772. doi:10.1161/Circresaha.118.312562

Gluckman, P. D., Beedle, A., \& Hanson, M. A. (2009). Principles of evolutionary medicine. Oxford University Press.

Gold, E. B., Bromberger, J., Crawford, S., Samuels, S., Greendale, G. A., Harlow, S. D., \& Skurnick, J. (2001). Factors associated with age at natural menopause in a multiethnic sample of midlife women. American Journal of Epidemiology, 153(9), 865-874. doi:10.1093/aje/153.9.865 
Gold, E. B., Crawford, S. L., Avis, N. E., Crandall, C. J., Matthews, K. A., Waetjen, L. E., ... Harlow, S. D. (2013). Factors related to age at natural menopause: Longitudinal analyses from SWAN. American Journal of Epidemiology, 178(1), $70-83$.

Gorrindo, T., Lu, Y., Pincus, S., Riley, A., Simon, J. A., Singer, B. H., \& Weinstein, M. (2007). Lifelong menstrual histories are typically erratic and trending: A taxonomy. Menopause - The Journal of the North American Menopause Society, 14(1), 7488. doi:10.1097/01.gme.0000227853.19979.7f

Gould, S. J., \& Lewontin, R. C. (1979). Spandrels of San-Marco and the Panglossian Paradigm - A critique of the adaptationist program. Proceedings of the Royal Society Series B - Biological Sciences, 205(1161), 581-598. doi:10.1098/rspb.1979.0086

Graham, W. J. (1998). Outcomes and effectiveness in reproductive health. Social Science \& Medicine, 47(12), 1925. doi:10.1016/s0277-9536(98)00334-7

Hammond, E. R., Green, M. P., Shelling, A. N., Berg, M. C., Peek, J. C., \& Cree, L. M. (2016). Oocyte mitochondrial deletions and heteroplasmy in a bovine model of ageing and ovarian stimulation. Molecular Human Reproduction, 22(4), 261-271. doi:10.1093/molehr/gaw003

Harding, J. (1997). Bodies at risk: Sex, surveillance and hormone replacement therapy. In A. R. Petersen \& R. Bunton (Eds.), Foucault, health and medicine. Routledge.

Hardy, C. (2019). Menopause and the workplace guidance: What to consider. Post Reproductive Health, 26(1), 43-45. https:// doi.org/10.1177/2053369119873257

Hardy, R., \& Kuh, D. (2002). Does early growth influence timing of the menopause? Evidence from a British birth cohort. Human Reproduction, 17(9), 2474-2479. doi:10.1093/humrep/17.9.2474

Hardy, R., \& Kuh, D. (2005). Social and environmental conditions across the life course and age at menopause in a British birth cohort study. Bjog - An International Journal of Obstetrics and Gynaecology, 112(3), 346-354. doi:10.1111/ j.147-0528.2004.00348.x

Harlow, S. D., \& Paramsothy, P. (2011). Menstruation and the menopausal transition. Obstetrics and Gynecology Clinics of North America, 38(3), 595-607. doi:10.1016/j.ogc.2011.05.010

Hawkes, K., \& Coxworth, J. E. (2013). Grandmothers and the evolution of human longevity: A review of findings and future directions. Evolutionary Anthropology, 22(6), 294-302.

Hawkes, K., O’Connell, J. F., Jones, N. G. B., Alvarez, H., \& Charnov, E. L. (1998). Grandmothering, menopause, and the evolution of human life histories. Proceedings of the National Academy of Sciences of the United States of America, 95(3), 1336-1339.

Henderson, K. D., Bernstein, L., Henderson, B., Kolonel, L., \& Pike, M. C. (2008). Predictors of the timing of natural menopause in the multiethnic cohort study. American Journal of Epidemiology, 167(11), 1287-1294. doi:10.1093/aje/kwn046

Hidaka, B. H., \& Boddy, A. M. (2016). Is estrogen receptor negative breast cancer risk associated with a fast life history strategy? Evolution, Medicine, and Public Health, 2016(1), 17. doi:10.1093/emph/eov034

Hillard, T., Abernethy, K., Hamoda, H., Shaw, I., Everett, M., Ayres, J., ... Currie, H. (2017). Management of the Menopause (6th edition) (Vol. 23). Slough: British Menopause Society.

Jasienska, G., Bribiescas, R. G., Furberg, A.-S., Helle, S., \& Núñez-de, L. M. (2017). Human reproduction and health: An evolutionary perspective. The Lancet, 390(10093), 510. doi:10.1016/s0140-6736(17)30573-1

Jasienska, G., Sherry, D. S., \& Holmes, D. J. (2017). The Arc of Life: Evolution and health across the life course. New York, NY: Springer.

Kaplan, H., Lancaster, J., \& Robson, A. (2003). Embodied capital and the evolutionary economics of the human life span. Population and Development Review, 29, 152.

Kato, I., Toniolo, P., Koenig, K. L., Shore, R. E., Zeleniuch-Jacquotte, A., Akhmedkhanov, A., \& Riboli, E. (1999). Epidemiologic correlates with menstrual cycle length in middle aged women. European Journal of Epidemiology, 15(9), 809-814. doi:10.1023/a:1007669430686

Kirkwood, T. B. L. (1977). Evolution of Aging. Nature, 270(5635), 301-304. doi:10.1038/270301a0

Kirkwood, T. B. L. (1999). Time of our lives: The science of human ageing. Weidenfeld \& Nicolson.

Kirkwood, T. B., \& Shanley, D. P. (2010). The connections between general and reproductive senescence and the evolutionary basis of menopause. Annals of the New York Academy of Science, 1204, 21-29.

Kirkwood, T. B. L., \& Westendorp, R. G. J. (2001). Human longevity at the cost of reproductive success: Trade-offs in the life history. In J. M. Robine, T. B. L. Kirkwood, \& M. Allard (Eds.), Sex and longevity: Sexuality, gender, reproduction, parenthood. Research and Perspectives in Longevity. Berlin, Heidelberg: Springer. https://doi.org/10.1007/978-3-642-59558-5_1

Koochmeshgi, J., Hosseini-Mazinani, S. M., Morteza Seifati, S., Hosein-Pur-Nobari, N., \& Teimoori-Toolabi, L. (2004). Apolipoprotein E genotype and age at menopause. Annals of the New York Academy of Science, 1019, 564-567. doi:10.1196/annals.1297.105

Laisk, T., Tšuiko, O., Jatsenko, T., Hõrak, P., Otala, M., Lahdenperä, M., ... Tapanainen, J. S. (2018). Demographic and evolutionary trends in ovarian function and aging. Human Reproduction Update. doi:10.1093/humupd/dmy031

Laland, K. N., Sterelny, K., Odling-Smee, J., Hoppitt, W., \& Uller, T. (2011). Cause and effect in biology revisited: Is Mayr's proximate-ultimate dichotomy still useful? Science, 334(6062), 1512-1516. doi:10.1126/science.1210879

Leidy, L. E., Godfrey, L. R., \& Sutherland, M. R. (1998). Is follicular atresia biphasic? Fertility and Sterility, 70(5), 851-859. doi:10.1016/S0015-0282(98)00316-1 
Levine, M. E., Lu, A. T., Chen, B. H., Hernandez, D. G., Singleton, A. B., Ferrucci, L., ... Horvath, S. (2016). Menopause accelerates biological aging. Proceedings of the National Academy of Sciences of the United States of America 113(33), 9327-9332. doi:10.1073/pnas.1604558113

Levitis, D. A., Burger, O., \& Lackey, L. B. (2013). The human post-fertile lifespan in comparative evolutionary context. Evolutionary Anthropology, 22(2), 66-79. doi:10.1002/evan.21332

Lin, W. N., Titus, S., Moy, F., Ginsburg, E. S., \& Oktay, K. (2017). Ovarian aging in women with BRCA germline mutations. Journal of Clinical Endocrinology \& Metabolism, 102(10), 3839-3847. doi:10.1210/jc.2017-00765

Lock, M. M. (1993). Encounters with aging: Mythologies of menopause in Japan and North America. University of California Press.

May-Panloup, P., Boucret, L., de la Barca, J. M. C., Desquiret-Dumas, V., Ferre-L'Hotellier, V., Moriniere, C., ... Reynier, P. (2016). Ovarian ageing: The role of mitochondria in oocytes and follicles. Human Reproduction Update, 22(6), $725-743$. doi:10.1093/humupd/dmw028

May-Panloup, P., Desquiret, V., Moriniere, C., Ferre-L'Hotellier, V., Lemerle, S., Boucret, L., ... Reynier, P. (2014). Mitochondrial macro-haplogroup JT may play a protective role in ovarian ageing. Mitochondrion, 18, 1-6. doi:10.1016/ j.mito.2014.08.002

Meng, F. T., Wang, Y. L., Liu, J., Zhao, J., Liu, R. Y., \& Zhou, J. N. (2012). ApoE genotypes are associated with age at natural menopause in Chinese females. Age, 34(4), 1023-1032. doi:10.1007/s11357-011-9287-4

The Million Women Study Collaborative, G. (1999). The Million Women Study: Design and characteristics of the study population. Breast Cancer Research, 1(1), 73-80. doi:10.1186/bcr16

Mishra, G., Hardy, R., \& Kuh, D. (2007). Are the effects of risk factors for timing of menopause modified by age? Results from a British birth cohort study. Menopause, 14(4), 717-724. doi:10.1097/gme.0b013e31802f3156

Mishra, G. D., Pandeya, N., Dobson, A. J., Chung, H. F., Anderson, D., Kuh, D., ... Weiderpass, E. (2017). Early menarche, nulliparity and the risk for premature and early natural menopause. Human Reproduction, 32(3), 679-686. doi:10.1093/ humrep/dew350

Monteleone, P., Mascagni, G., Giannini, A., Genazzani, A. R., \& Simoncini, T. (2018). Symptoms of menopause - Global prevalence, physiology and implications. Nature Reviews on Endocrinology, 14(4), 199-215. doi:10.1038/nrendo.2017.180 10.1038/nrendo.2017.180. Epub 2018 Feb 2.

Nabel, E. G. (2013). The Women's Health Initiative-A victory for women and their health. Jama, 310(13), 1349. doi:10.1001/ jama.2013.278042

Narkwichean, A., Maalouf, W., Baumgarten, M., Polanski, L., Raine-Fenning, N., Campbell, B., \& Jayaprakasan, K. (2017). Efficacy of dehydroepiandrosterone (DHEA) to overcome the effect of ovarian ageing (DITTO): A proof of principle double blinded randomized placebo controlled trial. European Journal of Obstetrics \& Gynecology and Reproductive Biology, 218, 39-48. doi:10.1016/j.ejogrb.2017.09.006

NCC-WCH. (2015). Menopause: Full Guideline. NICE.

Nepomnaschy, P. A., Rowlands, A., Costa, A. P. P., \& Salvante, K. G. (2020). Socio-ecological challenges as modulators of women's reproductive trajectories. Annual review of anthropology, 49(1). doi:10.1146/annurev-anthro-102317-045930

Nesse, R. M., Bergstrom, C. T., Ellison, P. T., Flier, J. S., Gluckman, P., Govindaraju, D. R., ... Valle, D. (2010). Making evolutionary biology a basic science for medicine. Proceedings of the National Academy of Sciences, 107, 1800. doi:10.1073/ pnas.0906224106

Nettle, D. (2010). Dying young and living fast: Variation in life history across English neighborhoods. Behavioral Ecology, 21 (2), 387. doi:10.1093/beheco/arp202

Noguera, J. (2017). Interacting effects of early dietary conditions and reproductive effort on the oxidative costs of reproduction. PeerJ, 5(3). doi:10.7717/peerj.3094

Ossewaarde, M. E., Bots, M. L., Verbeek, A. L. M., Peeters, P. H. M., van der Graaf, Y., Grobbee, D. E., \& van der Schouw, Y. T. (2005). Age at menopause, cause-specific mortality and total life expectancy. Epidemiology, 16(4), 556-562. doi:10.1097/ 01.ede.0000165392.35273.d4

Packer, C. (2001). The ecology of menopause. In J. M. Robine, T. B. L. Kirkwood, \& M. Allard (Eds.), Sex and longevity: Sexuality, gender, reproduction, parenthood. Research and Perspectives in Longevity (pp. 91-101). Berlin, Heidelberg: Springer. https://doi.org/10.1007/978-3-642-59558-5_1

Padamsee, T. J. (2011). The pharmaceutical corporation and the 'good work' of managing women's bodies. Social Science \& Medicine, 72(8), 1342-1350. doi:https://doi.org/10.1016/j.socscimed.2010.10.034

Paramsothy, P., Harlow, S. D., Nan, B., Greendale, G. A., Santoro, N., Crawford, S. L., ... Randolph, J. F., Jr (2017). Duration of the menopausal transition is longer in women with young age at onset: The multiethnic Study of Women's Health Across the Nation. Menopause, 24(2), 142-149.

Peccei, J. S. (2001). Menopause: Adaptation or epiphenomenon? Evolutionary Anthropology: Issues, News, and Reviews, 10(2), 43-57. doi:10.1002/evan.1013

Pickard, S. (2019). From the third age to the third sex: A feminist framework for the life course. J Aging Stud, 49, 56-65. doi:10.1016/j.jaging.2019.04.003

Rautalahti, M., Albanes, D., Virtamo, J., Palmgren, J., Haukka, J., \& Heinonen, O. P. (1993). Lifetime menstrual activity Indicator of breast-cancer risk. European Journal of Epidemiology, 9(1), 17-25. doi:10.1007/Bf00463085 
Rodstrom, K., Bengtsson, C., Milsom, I., Lissner, L., Sundh, V., \& Bjourkelund, C. (2003). Evidence for a secular trend in menopausal age: A population study of women in Gothenburg. Menopause, 10(6), 538-543. doi:10.1097/01.GME. 0000094395.59028.0F

Rossouw, J. E., Anderson, G., \& Oberman, A. (2003). Foreword: The Women's Health Initiative baseline summary. Annals of Epidemiology, 13(9), S1-S4. doi:10.1016/S1047-2797(03)00041-3

Rowe, J. W., \& Kahn, R. L. (2015). Successful aging 2.0: Conceptual expansions for the 21st century. Journal of Gerontology B: Psychological Science and Social Science, 70(4), 593-596. doi:10.1093/geronb/gbv025

Ruth, K. S., Perry, J. R. B., Henley, W. E., Melzer, D., Weedon, M. N., \& Murray, A. (2016). Events in early life are associated with female reproductive ageing: A UK Biobank Study. Scientific Reports, 6(1), 24710. doi:10.1038/srep24710

Ryan, C. P., Hayes, M. G., Lee, N. R., McDade, T. W., Jones, M. J., Kobor, M. S., ... Eisenberg, D. T. A. (2018). Reproduction predicts shorter telomeres and epigenetic age acceleration among young adult women. Scientific Reports, 8. doi:ARTN 11100 10.1038/s41598-018-29486-4

Schoenaker, D. A. J. M., Jackson, C. A., Rowlands, J. V., \& Mishra, G. D. (2014). Socioeconomic position, lifestyle factors and age at natural menopause: A systematic review and meta-analyses of studies across six continents. International Journal of Epidemiology, 43(5), 1542-1562. doi:10.1093/ije/dyu094

Schoenbaum, E. E., Hartel, D., Lo, Y. T., Howard, A. A., Floris-Moore, M., Arnsten, J. H., \& Santoro, N. (2005). HIV infection, drug use, and onset of natural menopause. Clinical Infectious Diseases, 41(10), 1517-1524. doi:10.1086/497270

Sear, R. (2016). Beyond the nuclear family: An evolutionary perspective on parenting. Current Opinion in Psychology, 7, 98103. doi:10.1016/j.copsyc.2015.08.013

Sheppard, P., \& Van Winkle, Z. (2020). Using sequence analysis to test if human life histories are coherent strategies. Evolutionary Human Sciences, 2, e39. doi:10.1017/ehs.2020.38

Sievert, L. L. (2006). Menopause: A Biocultural Perspective: Rutgers University Press.

Sievert, L. L. (2014). Anthropology and the study of menopause: Evolutionary, developmental, and comparative perspectives. Menopause - The Journal of the North American Menopause Society, 21(10), 1151-1159. doi:10.1097/gme. 0000000000000341

Skjaervo, G. R., \& Roskaft, E. (2013). Menopause: No support for an evolutionary explanation among historical Norwegians. Experimental Gerontology, 48(4), 408-413. doi:10.1016/j.exger.2013.02.001

Stearns, S. C. (1992). The evolution of life histories. Oxford University Press.

Stearns, S. C. (2012). Evolutionary medicine: Its scope, interest and potential. Proceedings. Biological Sciences, 279(1746), 4305. doi:rspb.2012.1326 [pii]

Stearns, S. C., Ackermann, M., Doebeli, M., \& Kaiser, M. (2000). Experimental evolution of aging, growth, and reproduction in fruitflies. Proceedings of the National Academy of Sciences of the United States of America, 97(7), 3309. doi:10.1073/ pnas.97.7.3309

Stolk, L., Perry, J. R. B., Chasman, D. I., He, C. Y., Mangino, M., Sulem, P., ... Study, L. C. (2012). Meta-analyses identify 13 loci associated with age at menopause and highlight DNA repair and immune pathways. Nature Genetics, 44(3), 260-268. doi:10.1038/ng.1051

Strassmann, B. I. (1997). The biology of menstruation in Homo sapiens: Total lifetime menses, fecundity, and nonsynchrony in a natural-fertility population. Current Anthropology, 38(1), 123.

Strassmann, B. I. (1999). Menstrual cycling and breast cancer: An evolutionary perspective. Journal of Women's Health, 8(2), 193. doi:10.1089/jwh.1999.8.193

Takahashi, M., Singh, R. S., \& Stone, J. (2017). A theory for the origin of human menopause. Frontiers in Genetics, 7. doi:10.3389/fgene.2016.00222

Tamura, H., Kawamoto, M., Sato, S., Tamura, I., Maekawa, R., Taketani, T., ... Sugino, N. (2017). Long-term melatonin treatment delays ovarian aging. Journal of Pineal Research, 62(2). doi:10.1111/jpi.12381

Tatone, C., \& Amicarelli, F. (2013). The aging ovary - The poor granulosa cells. Fertility and Sterility, 99(1), $12-17$. doi:10.1016/j.fertnstert.2012.11.029

Tempfer, C. B., Riener, E. K., Keck, C., Grimm, C., Heinze, G., Huber, J. C., ... Hefler, L. A. (2005). Polymorphisms associated with thrombophilia and vascular homeostasis and the timing of menarche and menopause in 728 white women. Menopause, 12(3), 325-330.

Towner, M. C., Nenko, I., \& Walton, S. E. (2016). Why do women stop reproducing before menopause? A life-history approach to age at last birth. Philosophical Transactions of the Royal Society B-Biological Sciences, 371(1692). doi:10.1098/rstb.2015.0147

USC Programme on Global Ageing, Health, \& Policy. (2018). Gateway to Global Aging Data, produced by the USC Program on Global Aging, Health \& Policy, with funding from the National Institute on Aging. Retrieved from https://g2aging.org/?

Wang, T. R., Zhang, M., Jiang, Z. L., \& Seli, E. (2017). Mitochondrial dysfunction and ovarian aging. American Journal of Reproductive Immunology, 77(5). doi:10.1111/aji.12651

Wells, J. C. K., Nesse, R. M., Sear, R., Johnstone, R. A., \& Stearns, S. C. (2017). Evolutionary public health: Introducing the concept. The Lancet, 390(10093), 500. doi:10.1016/s0140-6736(17)30572-x

Wiley, A. S., \& Cullin, J. M. (2020). Biological normalcy. Evolution, Medicine, and Public Health, 2020(1), 1. doi:10.1093/ emph/eoz035 
Williams, G. C. (1957). Pleiotropy, natural selection, and the evolution of senescence. Evolution, 11(4), 398. doi:10.1111/ j.1558-5646.1957.tb02911.x

Yang, Y., Arnot, M., \& Mace, R. (2019). Current ecology, not ancestral dispersal patterns, influences menopause symptom severity. Ecology and Evolution, 9(22), 12503-12514. doi:10.1002/ece3.5705

Zhang, J. J., Fang, L., Lu, Z. Y., Xiong, J. Q., Wu, M., Shi, L. Y., ... Wang, S. X. (2016). Are sirtuins markers of ovarian aging? Gene, 575(2), 680-686. doi:10.1016/j.gene.2015.09.043

Zhang, D. D., Zhang, X. Q., Zeng, M., Yuan, J. H., Liu, M. Y., Yin, Y., ... Liu, L. (2015). Increased DNA damage and repair deficiency in granulosa cells are associated with ovarian aging in rhesus monkey. Journal of Assisted Reproduction and Genetics, 32(7), 1069-1078. doi:10.1007/s10815-015-0483-5

Cite this article: Fraser A, Johnman C, Whitley E, Alvergne A (2020). The evolutionary ecology of age at natural menopause: implications for public health. Evolutionary Human Sciences 2, e57, 1-21. https://doi.org/10.1017/ehs.2020.59 